\title{
Necessity of Professional Access to Strength and Conditioning Coaches in China
}

\author{
Yan $\mathrm{Li}^{12}$ \\ ${ }^{1 .}$ Hebei Institute of Physical Education 050041 \\ 2. Institute of Physical Education, Hebei Normal University050024 \\ 82 Xuefu Road, Shijiazhuang, Hebei 050041 China \\ Email: 878578182@qq.com
}

\begin{abstract}
From the emergence, development and demand situation of the strength and conditioning coaches at home and abroad, the necessity of professional access to strength and conditioning coaches is analyzed from five aspects as below: it can solve the specialized and professional training of the strength and conditioning coaches; mobilize social forces to participate in the work of strength and conditioning coaches, broaden the ways of cultivating the strength and conditioning coaches; improve the severe shortage of the strength and conditioning coaches, and enhance the scientific level of the physical training; fully improve the professional qualification and comprehensive quality of the strength and conditioning coaches, so as to enhance the training quality of the talents for competitive sports; and play an important role in establishing and perfecting the new career development and promotion system in sports industry, enriching the occupational categories of sports industry and promoting the employment.
\end{abstract}

Keywords: China; strength and conditioning coach; professional access; necessity

Modern athletic training is a large system project, and its core is to cultivate the athletic ability of the athletes by scientific means and methods and lay a solid foundation for achieving excellent sport performance. However, as an important part of the high-level scientific training of the competitive sports, the strength and conditioning training is an important basis and fundamental guarantee to improve and give play to the overall athletic ability of the athletes. Creating the excellent sport performance plays a significant role in improving the athletic ability.

\section{- I. THE EMERGENCE AND DEVELOPMENT OF FOREIGN SPORTS COACHES}

Internationally, the National Strength and Conditioning Association (hereinafter referred to as NSCA) is an excellent organization to cultivate the strength and conditioning coaches. It is a non-profit educational association, and founded in 1978; up to now, it has 33,000 members across 52 countries. According to the ranking of the development for American major industries issued by Bureau of Labor Statistics (BLS), the strength and conditioning industry has become a popular industry with a good development prospect and bigger demand. The annual profit of a small-scale American company specialized in strength and conditioning products is not less than $\$ 150$ million. AP (Athletes Performance), one of the main representatives, has established the global physical training and efficient service system which is "oriented with training demand, driven by the market benefit maximization, supported by scientific and technological talent teams, and centered on rapid research and development and the integration of knowledge-based approach".

II. THE EFFECT OF THE DEVELOPMENT OF CHINESE SPORTS CAUSE ON THE GENERATION OF THE DEMANDS FOR STRENGTH AND CONDITIONING COACHES

With the rapid development of modern competitive sports, the scientific training level is higher and higher; especially the division of coaching labor is clearer and clearer. Now, the high-level sports teams have more and more diversified coach teams, and change the previous situation that one coach tries to do everything all by himself. According to the current situation, some of the national and professional teams can hire the foreign strength and conditioning coaches with high salary; although these newly-introduced foreign coaches are excellent, they still have certain obstacles on the language and understanding of the domestic athletes, and will have a certain effect on the instruction of the athletes, sometimes even may mislead the athlete's training, and cause unnecessary athletic injury, occasionally affect the sport performance. However, most coaches of other teams act as the guest performers from track and field events. At present, there are few qualified strength and conditioning coaches in China; even there is no institution or organization in our country to promote the professionalization process of strength and conditioning coaches; and all strength and conditioning coaches are appointed by the national teams and professional clubs according to their own needs and degree of recognition, and generally hired as coaches or experts, but engaged in the same work as the foreign strength and conditioning coaches; therefore, from this perspective, the sustainable development of strength and conditioning training in China has been restricted invisibly.

\section{- III. NECESSITY OF PROFESSIONAL ACCESS TO STRENGTH AND CONDITIONING COACHES}

- A. The professional access to strength and conditioning coaches is the fundamental and prerequisite to solve the specialized and professional cultivation of strength and conditioning coaches.

Physical ability is a component of athletes' competitive ability. Physical training, technical and tactical training, psychological training and intelligence training constitute the whole of sports training. If the competitive ability of the athletes is taken as a pyramid (Fig. 3-2) 


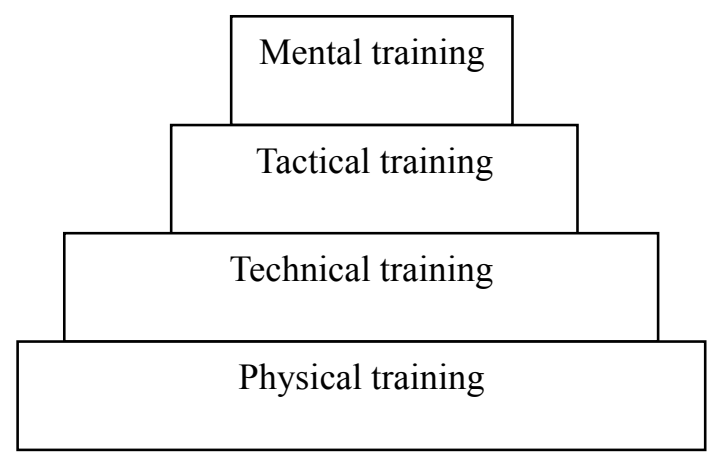

Fig 3-2 Pyramid of competitive ability of athletes

Physical training is not only the foundation of the pyramid; but also the fundamental to create performance; the foundation of physical training is more solid, the development degree of technical, tactical and metal training will be higher.

\section{- B. Professional access is beneficial for mobilizing} social forces to participate in the work of strength and conditioning coaches and broadening the ways of cultivating the strength and conditioning coaches;

Strengthening the professional research on the strength and conditioning coaches; discussing the particularity of the strength and conditioning coaches, establishing the related theoretical system of the professional access to the strength and conditioning coaches and instructing the training and employment of the strength and conditioning coaches has become an important object which needs to be solved urgently. The professional access to the strength and conditioning coaches can provide the opportunities to participate in the physical training through fair competition for those who engage in physical training, and will inevitably attract more people to pay attention to and understand the strength and conditioning coaches, so as to "further mobilize all social forces from policy markers to all walks of life". The special talents of strength and conditioning coaches are cultivated in scientific and unified way based on the vocational qualification examination of the strength and conditioning coaches, such practice is more beneficial for defining the direction of human resources education for the strength and conditioning coaches, guide the social education resources to cultivate the special talents for strength and conditioning coaches, mobilize other forces to participate in and monitor the work of strength and conditioning coaches.

\section{- C. Professional access is beneficial for improving the severe shortage of the strength and conditioning coaches and enhancing the scientific level of the physical training;}

Many researches and facts show that the strength and conditioning coaches play an important role in the training of competitive sports. Their quality level is an important factor to affect the development of competitive sports in China; especially with the development of modern science and technology, the international sports competition is increasingly fierce, the technical level and training level of sports also enter into a new stage; and the scientific training has made higher demands for the thought, business, management level and comprehensive ability of the strength and conditioning coaches. However, the qualified domestic strength and conditioning coaches are few; most of the sports teams and professional clubs hire the foreign strength and conditioning coaches. From a purely economic point of view, it needs to pay a big price. The actual demand of inverted pyramid distribution significantly contradicts with the positive pyramid structure of talent teams for strength and conditioning coaches. By virtue of professional access, the open employment mechanism can be established, so as to absorb the excellent talents widely. Moreover, due to the introduction of external competitive forces, the existing employees are promoted effectively, so as to stimulate the vitality of the existing teams and improve the overall level of strength and conditioning coaches as soon as possible. Meanwhile, the correct direction can be provided for the reform and development of educating the strength and conditioning coaches. If the scientific level of physical training is improved, then it is essential to set up the special position in the sports teams; how to select the excellent strength and conditioning coaches, stimulate them to give full play to the efficiency at the specific posts of the strength and conditioning coaches and achieve the continuous improvement of the scientific level for physical training, the professional access to strength and conditioning coaches is an inevitable choice.

\section{- D. Professional access is beneficial for fully improving the professional qualification and comprehensive quality of the strength and conditioning coaches, so as to enhance the training quality of the talents for competitive sports;}

The strength and conditioning coach is a demanding profession with very strong professional qualification and high comprehensive quality. If they are subject to professional access and screened strictly, then it is essential to guarantee that the members in the strength and conditioning coach teams accord with the complexity of the aforementioned knowledge on the mental ability; endow the strength and conditioning coaches with highly autonomy, so as to make them give play to their professional knowledge efficacy; eliminate the emotional disturbance and make objective and professional judgment according to scientific knowledge; prepare and establish the professional organizations, and maintain the professional quality of the practitioners through issuing or presenting a variety of certificates; formulate the unified professional norms and maintain the professional image of the practitioners. If everyone who desires to participate in the industry of strength and conditioning coaches follows the above-mentioned procedure, obtains the corresponding qualification certificates of the strength and conditioning coaches through scientific certification, then he can engage in the strength and conditioning coaches at last. In this way, the ability and right of the practitioner can be affirmed in the name of the state or government, and the social status of the practitioner can be improved accordingly. Then, the team of strength and 
conditioning coaches with varying quality and ability can be avoided maximally. It is beneficial for improving the overall professional qualification and comprehensive ability indeed for the strength and conditioning coaches, enhancing the ability to better development of the service transformation. In this case, it is possible to guarantee the cultivation quality of the reserve talents for competitive sports and improve the yield of the reserve talents for competitive sports.

\section{- E. Professional access plays an important role in} establishing and perfecting the new career development and promotion system in sports industry, enriching the occupation categories of sports industry and promoting the employment.

Professional access is to establish the theoretical system of the professional standards in conformity to the characteristics of strength and conditioning coaches from the perspective of the professional ability based on the scientific design and take it as fundamental basis for the strength and conditioning coaches to engage in the occupational activity, receive vocational education training and vocational skill appraisal as well as the staff recruiting and staffing. It instructs vocational education and vocational training reform of the strength and conditioning coaches, and provides the beneficial exploration for the establishment of the new career development system, and the standardization and management of sports talent market. The new career development of the strength and conditioning coaches and the establishment of the development system have a positive and practical significance to the effective solution on enriching the types of the current sports qualification certificates in China and the job requirements for the strength and conditioning coaches according to the sport market situation. Meanwhile, it also plays an important driving role in screening the construction and improvement of the theoretical system for the professional talents in Chinese sports industry.

\section{REFERENCES}

[1] Tang Mangguo, Overall framework construction on the system of occupational qualification certificate in Chinese sports industry [D] Nanjing: Nanjing Normal University, 2007.

[2] Li Zhi, The feasibility study on establishing the system of professional qualification for coaches in China [D]. Beijing: Beijing Sport University, 2004

[3] Liu Yue. The theoretical research on establishing the professional qualification certification standard of Chinese sport coaches [D] Changchun: Northeast Normal University, 2006.

[4] Duan Baotong, Research on education system of the coaches in major developed countries [D]. Beijing: Beijing Sport University, 2008

[5] Lv Hewu, Investigation and analysis on the research status of Chinese coaches for 30 years since the reform and opening up policy - Content analysis on 13 kinds of Chinese core journals in PE [D]. Shanghai: Shanghai Institute of Physical Education, 2010.

Li Yan (1979 - ), Associate professor, doctoral candidates, Research Interests: Sociology of Sport. 